\title{
ESTIMATION OF AEROSOL OPTICAL DEPTH OVER DEHRADUN (INDIA) USING SIMPLE MODEL FOR ATMOSPHERIC RADIATIVE TRANSFER IN MULTIPLE SCATTERING APPROXIMATION
}

\author{
M. Mehta ${ }^{\text {a, } *}$ \\ ${ }^{\text {a }}$ Photogrammetry and Remote Sensing Department, IIRS, Dehradun, manu@iirs.gov.in
}

Commission VI, WG VI/4

KEY WORDS: SMART, multiple scattering approximation, AWiFS, aerosol optical depth

\begin{abstract}
:
Aerosol optical depth retrieval over land surface using remote sensing employs the use of radiative transfer simulations and/or simultaneous measurements of atmospheric parameters at the time of satellite pass. Also, an accurate estimate of land surface parameters is also required in order to separate the atmospheric component from the land surface reflectance reaching at-sensor. In addition to empirical and semi-empirical approaches, amongst the most widely used methods to retrieve the aerosol properties from satellite measurements are radiative transfer codes used in either forward or inverse modes. As most of them are computationally complex, henceforth, efforts are made to formulate approximate models. In this study, we have tried to estimate aerosol optical depth using one such established physically based model, namely, SMART (Simple Model for Atmospheric Radiative Transfer) code in multiple scattering approximation for aerosols over first band $(0.52-0.59 \mu \mathrm{m})$ of RESOURCESAT-AWiFS sensor. The aim of the analysis was to find out an approach to decouple aerosol effects from Top of atmosphere signals recorded by AWiFS sensor using multiple scattering approximations for aerosols. The model is first calibrated for aerosol asymmetry parameter for one dataset each of summer and winter seasons respectively and subsequently validated for 4 different datasets ( 2 summer and 2 winter) against the MODIS atmosphere product for aerosol optical depth. The results show that the difference between simulated vs. MODIS AOD fall within MODIS expected errors for the aerosol product.
\end{abstract}

\section{INTRODUCTION}

Aerosols are known to have both direct and indirect effects on radiative forcing and thereby affecting climatic conditions. Hence, an accurate estimation of aerosols is necessary on microscopic and macroscopic levels so as to assess their impact on future scenarios of climate change. Networks like AERONET have been established worldwide to monitor the aerosols using remote sensing (Holben et al. 1998, Kaufman et al. 1997). In India, the effect of radiative forcing due to aerosols has been studied over some cities like Bangalore (Babu et al. 2002) and Ahmedabad (Ramachandran et al. 2010) which raises several issues that could impact regional climate and monsoon. Studies have been carried out to observe the effect of anthropogenic airborne mineral aerosols (Sokolik et al. 1996) and tropospheric aerosols (Haywood et al. 2000). It has been found that the direct climatic forcing by aerosols is sensitive to aerosol size and composition (Pilinis et al. 1995, Dubovik et al. 2002, Tegen et al. 1996). In order to have a synoptic view and to observe the aerosols globally, attempts have been made to retrieve aerosol optical thickness over oceans as well as land from remotely sensed imagery (Gordon et al. 1994, Von et al. 2003). In addition to shortwave bands (Torres et al. 1998), IR wavelengths are also used for aerosol sensing (Ackerman et al. 1997). Studies have shown that spectral multi-angle polarimetric observation may also prove useful to derive enhanced aerosol properties (Dubovik et al. 2010, Kokhanovsky et al. 2010). Some sensors like MODIS also provide processed atmosphere products over land surfaces (Chu et al. 2002). Most of the methods involving aerosol retrieval studies employ the use of radiative transfer models. Amongst the most common approaches to solve radiative transfer equations (RTE) is the method of discrete ordinates (Spurr et al. 2001). Methods involving neural networks are also used to solve the radiative transfer problem (Krishnan et al. 2012). Some fast models using line by line models and Monte Carlo methods which allow computation of high resolution spectra at a quicker pace (Fomin et al. 2012, Deutschmanna et al. 2010) are also in practice.

Most of the forward/inverse modelling approaches involve computational complexity and/or data intensive look up table methods. So efforts have been made by the researchers to find approximate models. This study focuses on the retrieval of aerosol optical depth from the first band of AWiFS sensor (0.52-0.59 $\mu \mathrm{m})$. The estimation is done by using an approximate but an established physically based model, i.e. SMART code (Simple Model for Atmospheric Radiative Transfer) (Seidel et al. 2010, Seidel et al. 2012, Kokhanovsky et al. 2005) which provides a suitable combination of speed and accuracy without using look up table approach. The author has earlier implemented the model in single scattering approximation aerosols over AWiFS data (Mehta et al. 2013a, Mehta et al. 2013b). In this study, the model is used in multiple scattering approximations for aerosols. The results have been compared against those from MODIS aerosol product. The importance of the study lies in exploring the potential of the model for its applicability over North Indian region by using one such Indian satellite sensor which is otherwise being widely used for estimation of land surface and biophysical parameters 
but not much explored for decoupling of atmospheric properties from surface reflectance signals reaching on-board.

\section{DATA AND STUDY AREA}

The study area chosen for analysis was Dehradun city which is the capital of Uttarakhand state of India (Fig.1). The site receives heavy rainfall during monsoon with a climate which is hot in summers and becomes very cold in winters. The annual temperature ranges from $27.9^{\circ} \mathrm{C}$ (average maximum) to $13.36^{\circ} \mathrm{C}$ (average minimum) respectively. Dehradun is surrounded by hills to its north and south and rivers to its east and west. There are some small scale industries located in the city. Aerosol observations over Dehradun show that the size of aerosols found in this place vary from 0.07 to 2 micron and dominated by fine mode particles (Rana et al. 2009).

The Top of atmosphere (TOA) reflectance was taken from AWiFS sensors on board Resourcesat 1 and 2 satellites. In totality, 6 different data sets for same study area of 3 years covering summer and winter seasons were used (Table 1). One image each for summer (12 May 2010) and winter (15 December 2010) seasons were selected for calibration of SMART model w.r.t. asymmetry parameter (Table 1). Once the aerosol asymmetry parameter was estimated, the model was applied to four more images combining the two seasons. Because of non-availability of ground/field measurements for the concurrent time period, the spectral land surface albedo was taken from MODIS product MCD43_A3 which was used as one of the model inputs. For the same reason, MODIS level 3 atmosphere product MOD08_L3 was also used for the calibration and validation purpose.

\subsection{AWiFS data}

AWiFS (Advanced Wide Field sensor) is a push broom sensor on board Resourcesat satellite which is realized in two electrooptic modules, AWiFS-A and AWiFS-B. The spatial resolution of the sensor is $56 \mathrm{~m}$ with four spectral bands i.e. green (B2: $0.52-0.59 \mu \mathrm{m})$, red (B3: 0.62-0.64 $\mu \mathrm{m})$, near infra-red (B4: 0.77$0.86 \mu \mathrm{m})$ and shortwave infra-red (B5: 1.55-1.77 $\mu \mathrm{m}$ ) respectively. The combined swath of the two modules is 737 $\mathrm{km}$. The present study utilizes TOA radiance/reflectance obtained in the green wavelength region of the sensor (IRS-P6 Data User's Manual). The calibration of this band is a progressively increasing sequence of sixteen intensity levels through exposure control.

\subsection{MODIS data}

MODIS is a near-polar satellite in sun synchronous orbit with Terra (descending node) and Aqua (ascending node) sensors respectively. The swath of the sensor is $2330 \mathrm{~km}$ (cross track) by $10 \mathrm{~km}$ (along track). There are 36 spectral bands with varying spatial resolutions. Bands 1-2 have spatial resolution of $250 \mathrm{~m}$, bands 3-7 and bands 8-36 are at spatial resolutions of $500 \mathrm{~m}$ and $1000 \mathrm{~m}$ respectively. In this study MODIS land surface reflectance BRDF/albedo parameter product MCD43_A3 (Strahler et al. 1999) has been used which provides both directional and bi-hemispherical reflectance at $500 \mathrm{~m}$ resolution as 16-days aggregate. As ground measurements of spectral land surface albedo were not available, the same were calculated from MODIS product. In addition, aerosol optical depth obtained from MODIS atmosphere level 3 MOD08_L3 product (Hubanks et al. 2008) at 1 degree grid was used for calibration and validation purposes.

\section{METHODOLOGY}

The simulation of TOA reflectance through SMART requires land surface albedo and atmospheric conditions as inputs to the model. Though, the surface albedo is taken from MODIS, the model first needs to be calibrated for aerosol parameters. The aerosol properties used in the model are single scattering albedo and aerosol asymmetry parameter. There are some small scale industries in Dehradun but the site is also not heavily polluted which guided us to choose aerosol single scattering albedo close to 1 (0.9). In general, for cloudless atmosphere, the value of asymmetry factor ranges from 0.1 under very clean conditions to 0.75 in the polluted situations in the considered wavelength range of interest (Zege et al. 1991). The atmospheric conditions of Dehradun suggests that neither it is a very clean site e.g., Nainital which is approximately $270 \mathrm{~km}$ from Dehradun where asymmetry parameter should be small, nor very polluted site e. g., Delhi which is approximately $250 \mathrm{~km}$ from Dehradun where asymmetry parameter ranges from $0.6-0.7$. As the measurements of asymmetry parameter were not available specifically for the area of interest, hence the SMART model in multiple scattering approximation was first calibrated for aerosol asymmetry parameter for summer and winter seasons respectively.

One AWiFS image each was chosen for both the seasons and the Top of atmosphere reflectance $\left(\mathrm{R}_{\mathrm{TOA}}\right)$ was calculated from the Digital Number (DN) image using the calibration constants (Qcal $\max$, Qcal $_{\text {min }}$ ) provided with the metadata file (1).

$$
\begin{gathered}
\mathrm{R}_{\mathrm{TOA}}=\frac{\pi \mathrm{d}^{2}}{\mathrm{E}_{\mathrm{gol}} * \cos \theta_{g}} *\left\{\frac{\left(\mathrm{L}_{\max }-\mathrm{L}_{\min }\right) *\left(\mathrm{DN}-\mathrm{Q}_{\mathrm{calmin}}\right)}{\left(\mathrm{Q}_{\mathrm{calmax}}-\mathrm{Q}_{\mathrm{cal} \min )}\right.}\right. \\
\left.+\mathrm{L}_{\text {min }}\right\}
\end{gathered}
$$

where

$\mathrm{E}_{\text {sol }}=$ exo-atmospheric solar irradiance

$\Theta_{\mathrm{s}}=$ solar zenith angle

$\mathrm{DN}=$ Digital number

$\mathrm{L}_{\max }=$ spectral at-sensor radiance scaled to $\mathrm{Qcal}_{\max }$

$\mathrm{L}_{\min }=$ spectral at-sensor radiance scaled to $\mathrm{Qcal}_{\min }$

Qcal $\max =$ maximum quantized calibrated pixel value

$\mathrm{Qcal}_{\min }=$ minimum quantized calibrated pixel value

The TOA reflectance function is composed of molecular, aerosol and surface reflectance functions respectively (2)

$$
\mathrm{R}_{\mathrm{TOA}}=\mathrm{R}_{\text {Ray }}+\mathrm{R}_{\mathrm{SFC}}+\mathrm{R}_{\text {Aero }}
$$

where

$\mathrm{R}_{\text {Ray }}=$ Molecular reflectance in Rayleigh approximation

$\mathrm{R}_{\mathrm{SFC}}=$ Surface reflectance

$\mathrm{R}_{\text {Aero }}=$ reflectance function of aerosols

The molecular reflectance function is calculated by taking Rayleigh approximation into consideration. The surface reflectance is computed by using the transmission in upward and downward directions along with surface albedo inputs. Aerosol reflectance function on the other hand is a complex function which takes into account the phase function of aerosols along with the multiple scattering components. The spectral 
land surface albedo was taken from MODIS product MCD43_A3 for the corresponding wavelength region as that of the first AWiFS band. The transmittance (direct + diffused) and spherical albedo (S) of the atmosphere was calculated using the parameterization equations (Kokhanovsky et al. 2005). It is important to note here that this parameterization is valid for asymmetry parameters $\epsilon[0,0.9]$, zenith angles $\epsilon[0.2,1.0]$ and AOD $\epsilon[0,2]$. This range covers the possible variability of AOD and observation geometries for the area under the study.

To calibrate the model, the spectral AOD $\left(\tau^{\text {aer }}\right)$ was taken from MODIS product MOD08_L3. Once the aerosol asymmetry parameter was estimated for each of the two seasons in the calibration process, the SMART model was run in order to find out spectral aerosol depths for other time periods. The results were compared against those obtained from MODIS product MOD08_L3 as the simultaneous measurements using ground instruments were not available for the all the dates considered. Figure 2 illustrates the overall methodology used in the analysis.

It may be of interest to note here that as the spatial resolutions of the AWiFS and MODIS products are different, the AWiFS data was re-sampled using nearest neighbor method to match with the spatial resolution of MODIS albedo product.

\section{REFERENCES}

Ackerman S. A. 1997. Remote sensing aerosols using satellite infrared observations. Journal of Geophysical Research, 102, D14, pp. 17,069-17,079, doi: 10.1029/96JD03066.

Babu S. S., Satheesh S. K. and K. Krishna Moorthy. 2002. Aerosol radiative forcing due to enhanced black carbon at an urban site in India." Geophysical Research Letters, 29, 18: 1880, doi: 10.1029/2002GL015826.

Chu D. A., Kaufman Y. J., Ichoku C., Remer L. A., Tanre’ D. and Holben B. N. 2002. Validation of MODIS aerosol optical depth retrieval over land. Geophysical Research Letter, 29, 12: 1617, doi: 10.1029/2001GL013205.

Deutschmanna, T., Beirle S., Frie U., Grzegorski M., Kerna C., Kritten L., Platt U., Prados-Román C., Pukite J., Wagner T., Werner B. and Pfeilsticker K. 2011. The Monte Carlo atmospheric radiative transfer model McArtim: Introduction and validation of Jacobians and 3D features. Journal of Quantitative Spectroscopy and Radiative Transfer, 112, 6, 1119-1137, doi:10.1016/j.jqsrt.2010.12.009.

Dubovik O., Holben B., Eck T. F., Smirnov A., Kaufman Y. J., King M. D., Tanre' D. and Slutsker I. 2002. Variability of

\section{RESULTS}

The AWiFS data is at a spatial resolution of $56 \mathrm{~m}$, whereas the surface albedo from MODIS is available at $500 \mathrm{~m}$ resolution. Hence, the AWiFS data was first re-sampled (using ENVI software) to match up with MODIS albedo resolution. Then, 5 homogeneous pixels were chosen for each of the dates (this involves approximately $9 \times 9 \times 5$ cloud free pixels of AWiFS original datasets). The average AOD for these pixels was calculated and was compared with MODIS AOD for the same location. In this comparison, it was assumed that AOD remains constant over an area of $1^{\circ} \mathrm{X} 1^{\circ}$.

The SMART model was calibrated in aerosol multiple scattering mode for 12 May 2010 and 15 Dec 2010 datasets respectively. The aerosol asymmetry parameter were calculated for each of the two seasons for the given study area and was applied for the four more dates. It was found that the results agreed quite well with those of MODIS products. There was a maximum difference of 0.097 for one of the dates (Fig. 4) and the individual differences fell within the uncertainty of MODIS L3 AOD product (Ruiz-Arias et al. 2013) for the five dates under study (Table 2). It is to be noted here that the MODIS L3 expected error was calculated as per South Asian region.

It is found that there is an average uncertainty of 0.023 due to ozone optical depth which is also estimated by taking ozone measurements from MODIS product. The differences could further be attributed to the difference in time of image acquisitions and relative spectral response of the two sensors and also due to an independent estimate of surface albedo (from MODIS). Nevertheless the approach is found to be suitable for estimation of aerosol optical depth from the sensor under consideration for the study area taken into account. Future work will focus on including more number of datasets and applying the approach over more number of study locations.

Absorption and Optical Properties of Key Aerosol Types Observed in Worldwide Locations. Journal of the Atmospheric Sciences, 59(3), 590-608.

Dubovik O., Herman M. Holdak A., Lapyonok T., Tanre’ D., Deuze' J. L., Ducos F., Sinyuk A. and Lopatin A. 2010. Statistically optimized inversion algorithm for enhanced retrieval of aerosol properties from spectral multi-angle polarimetric satellite observations. Atmos. Meas. Tech. Discuss., 3, 4967-5077, www.atmos-meas-techdiscuss.net/3/4967/2010/doi:10.5194/amtd-3-4967-2010.

Fomin B. and Falaleeva V. 2012. A Polarized Atmospheric Radiative Transfer Model for Calculations of Spectra of the Stokes Parameters of Shortwave Radiation Based on the Lineby-Line and Monte Carlo Methods. Atmosphere, 3(4), 451-467, doi: 10.3390/atmos3040451.

Gordon H. R. and Wang M. 1994. Retrieval of water-leaving radiance and aerosol optical thickness over the oceans with SeaWiFS: a preliminary algorithm. Applied Optics, 33(3), 443452. 
Haywood and Boucher O. 2000. Estimates of the direct and indirect radiative forcing due to tropospheric aerosols' A review. Reviews of Geophysics, 38(4), 513-543.

Holben B. N., Eck T. F., Slutsker I., Tanre’ D., Buisk J. P., Setzer A., Vermote E., Reagan J. A., Kaufman Y. J., Nakajima T., Lavenu F., Jankowiak I. and Smirnov A. 1998. AERONET-A Federated Instrument Network and Data Archive for Aerosol Characterization. Remote Sens. Environ., 66, 1-16, doi: 10.1016/50034-4257(98)00031-5.

Henyey L. and Greenstein J. 1993. Diffuse radiation in the galaxy. Astrophys. J., 93, 70-83.

Hubanks, King, Platnick, and Pincus. 2008. MODIS Atmosphere L3 Gridded Product Algorithm Theoretical Basis Document, ATBD-MOD-3.

IRS-P6 Data User's Manual, of NRSA, Document No: IRSP6/NRSA/NDC/HB-10/03, edition: Oct. 1, 2003, http://www.euromap.de/download/P6_data_user_handbook.pdf

Kaufman Y. J., Tanre' D., Remer L. A., Vermote E. F., Chu A. and Holben B. N. 1997. Operational remote sensing of tropospheric aerosol over land from EOS moderate resolution imaging spectroradiometer Journal of Geophysical Research, 102, D14, 051-,067.

Kokhanovsky A., Mayer B. and Rozanov V. V. 2005. A parameterization of the diffuse transmittance and reflectance for aerosol remote sensing problems. Atmospheric Research, 73, $37-43$.

Kokhanovsky A. A., Deuz'e J. L., Diner D. J., Dubovik O., Ducos F., Emde C., Garay M. J., Grainger R. G., Heckel A., Herman M., Katsev I. L., Keller J., Levy R., North P. R. J., A. Prikhach S., Rozanov V. V., Sayer A. M., Ota Y., Tanr'e D., Thomas G. E. and Zege E P. 2010. The inter-comparison of major satellite aerosol retrieval algorithms using simulated intensity and polarization characteristics of reflected light. Atmos. Meas. Tech., 3, 909-932, www.atmos-meastech.net/3/909/2010/doi:10.5194/amt-3-909-2010.

Krishnan P., Ramanujam K. S. and Balaji C. 2012. An artificial neural network based fast radiative transfer model for simulating infrared sounder radiances. Journal of Earth System Science, 121(4). 891-901.

Manu M., Payal G. and Kautilya N. 2013a. Implementation of SMART Radiative Transfer code in single scattering approximation for retrieval of aerosol optical depth over Dehradun. Journal of Applied Remote Sensing, J. Appl. Remote Sens. 7 (1), 073521 (August 19, 2013); doi: 10.1117/1.JRS.7.073521.

Manu M., Kautilya N. and Payal G. 2013b. Retrieval of midvisible land surface albedo over Dehradun, Northern India and its sensitivity to atmospheric parameters. Current Science, 105(5), 578-579.

Pilinis C., Pandis S. N. and Seinfeld J. H. 1995. Sensitivity of direct climate forcing by atmospheric aerosols to aerosol size and composition. Journal of Geophysical Research, 100, D9, 18739-18754, doi:10.1029/95JD02119.
Rana S., Kant Y. and Dadhwal V. K. 2009. Diurnal and Seasonal Variation of Spectral Properties of Aerosols over Dehradun, India. Aerosol and Air Quality Research, 9(1), 3249.

Ramachandran S. and Kedia S. 2010. Black carbon aerosols over an urban region: Radiative forcing and climate impact," Journal of Geophysical Research, 115, D10202, doi: 10.1029/2009JD013560.

Ruiz-Arias J. A., Dudhia J., Gueymard C. A., and PozoV'azquez D. 2013. Assessment of the Level-3 MODIS daily aerosol optical depth in the context of surface solar radiation and numerical weather modeling, Atmos. Chem. Phys., 13, 675692, doi:10.5194/acp-13-675-2013.

Seidel F. C., Kokhanovsky A. A. and Schaepman M. E. 2010. Fast and simple model for atmospheric radiative transfer. Atmos. Meas. Tech, 3, 1129-1141, doi : 10.5194/amt-3-11292010.

Seidel F. C., Kokhanovsky A. A. and Schaepman M. E. 2012. Fast retrieval of aerosol optical depth and its sensitivity to surface albedo using remote sensing data. Atmospheric Research, 116, 22-32.

Sokolik I. N. and Toon O. B. 1996. Direct radiative forcing by anthropogenic airborne mineral aerosols. Nature, 381, 681 683, doi: 10.1038/381681a0.

Spurr R. J. D., Kurosu T. P. and Chance K. V. 2001. A linearized discrete ordinate radiative transfer model for atmospheric remote-sensing retrieval. Journal of Quantitative Spectroscopy \& Radiative Transfer, 68, 689-735.

Stephens G. L., 1994. Remote Sensing of the Lower Atmosphere, Oxford University Press, New York.

Strahler A. H., Wanner W., Schaaf C. B., Li X., Hu B., Muller J. P., Lewis P. and Barnsley M. J. 1999. MODIS BRDF/Albedo product: Algorithm theoretical basis document, Version 5.0.

Tegen I. and Lacis A. A. 1996. Modeling of particle size distribution and its influence on the radiative properties of mineral dust aerosol. Journal of Geophysical Research, 101, D14, 237-244.

Torres O., Bhartia P. K., Herman J. R., Ahmad Z. and Gleason J. 1998. Derivation of aerosol properties from satellite measurements of backscattered ultraviolet radiation: Theoretical basis. Journal of Geophysical Research, 103, D14, pp. 17,09917,110, doi: 1998. 10.1029/98JD00900.

Von W. H., Freitag M. and Burrows J. B. 2003. Retrieval of aerosol optical thickness over land surfaces from top-ofatmosphere radiance. Journal of Geophysical Research, 108, D9, 4260, doi: 10.1029/2001JD002018.

Zege E. P., Ivanov A. P. and Katsev I. L. 1991. Image transfer through a scattering medium. New York: Springer-Verlag. 


\section{FIGURES}

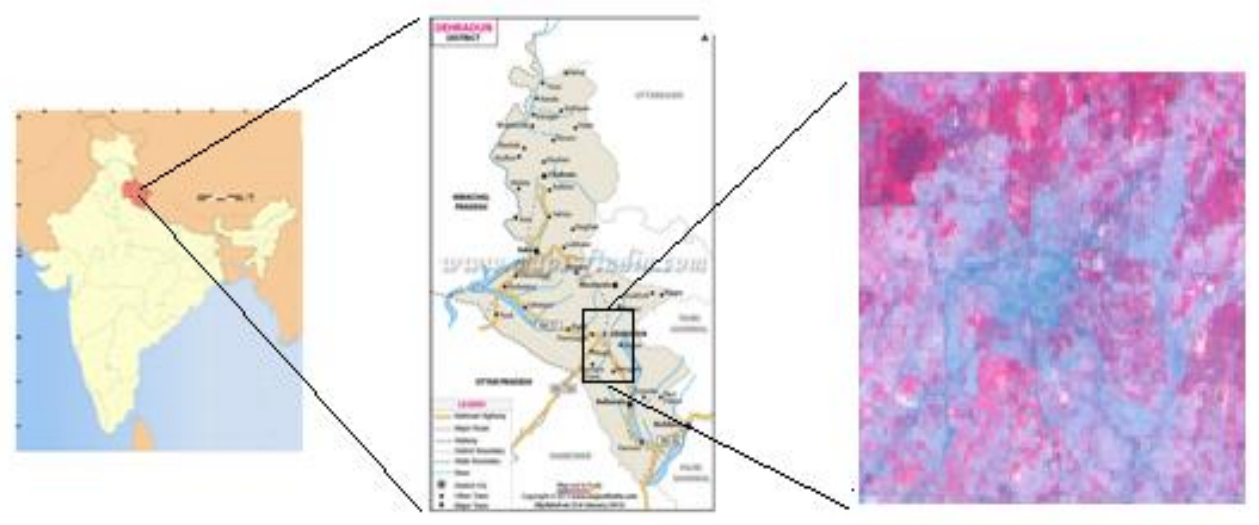

Figure 1: Area under study

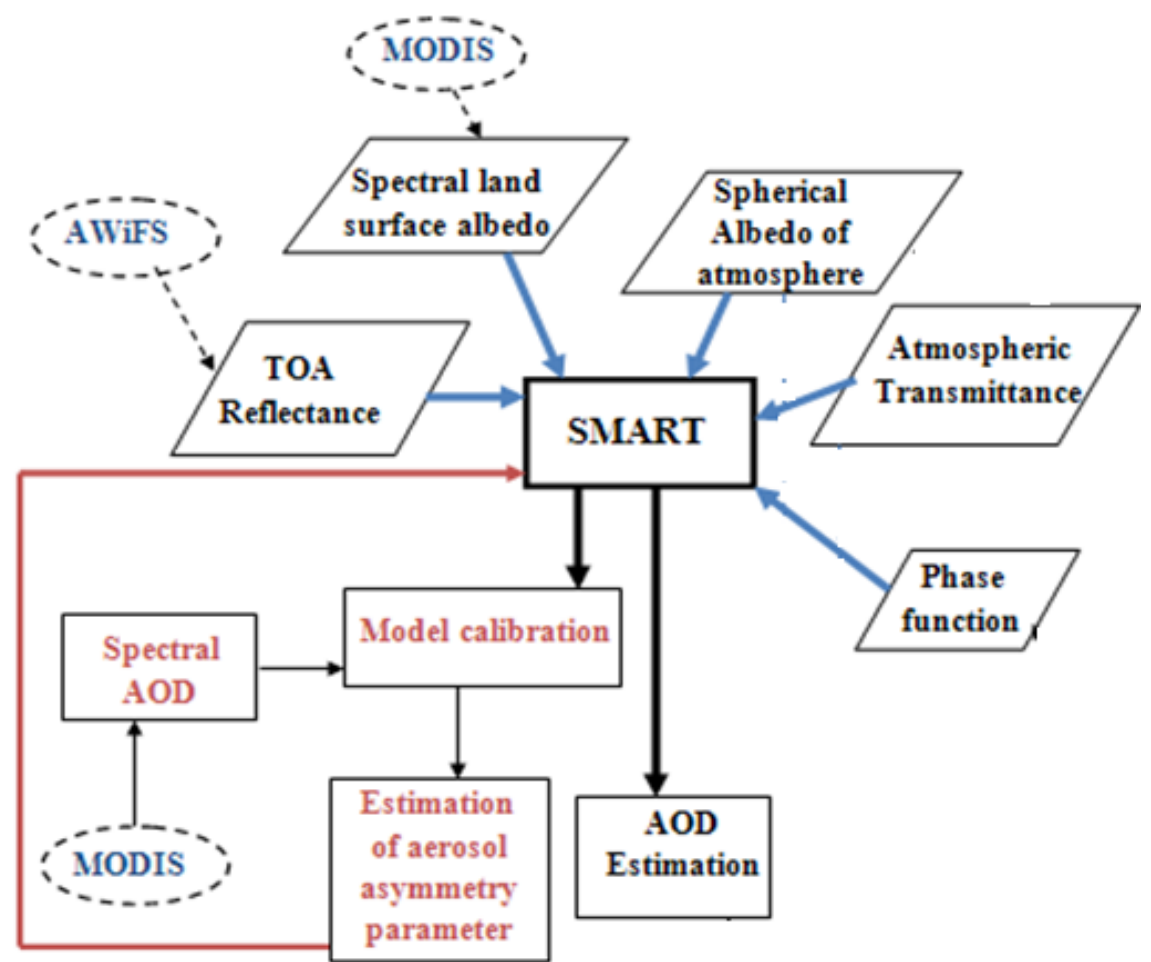

Figure 2 Methodology 


\section{TABLES}

Table 1: AWiFS data used in the study

\begin{tabular}{|c|c|}
\hline Dates & Purpose \\
\hline $26 / 02 / 2007$ & Validation \\
\hline $23 / 05 / 2007$ & Validation \\
\hline $12 / 05 / 2010$ & Calibration \\
\hline $15 / 12 / 2010$ & Calibration \\
\hline $12 / 05 / 2011$ & Validation \\
\hline $22 / 12 / 2011$ & Validation \\
\hline
\end{tabular}

Table 1 Comparison of simulated and MODIS AOD

\begin{tabular}{|c|c|c|c|c|}
\hline Date (DD/MM/YYYY) & $\mathbf{2 6 / 0 2 / 2 0 0 7}$ & $\mathbf{2 3 / 0 5 / 2 0 0 7}$ & $\mathbf{1 2 / 0 5 / 2 0 1 1}$ & $\mathbf{2 2 / 1 2 / 2 0 1 1}$ \\
\hline AOD & 0.377 & 0.400 & 0.570 & 0.183 \\
\hline MODIS AOD & 0.354 & 0.303 & 0.517 & 0.168 \\
\hline $\begin{array}{c}\text { Difference (Simulated- } \\
\text { MODIS) }\end{array}$ & 0.022 & 0.097 & 0.053 & 0.015 \\
\hline $\begin{array}{c}\text { Expected error MODIS } \\
\text { Ozone Optical Depth }\end{array}$ & 0.142 & 0.135 & 0.171 & 0.120 \\
\hline
\end{tabular}

